\title{
Temperament and Character in Euthymic Major Depressive Disorder Patients: The Effect of Previous Suicide Attempts and Psychotic Mood Episodes
}

\author{
Okan Ekinci ${ }^{凶}$, Yakup Albayrak ${ }^{2}$ and Aslı Erkan Ekinci ${ }^{1}$ \\ 'Department of Psychiatry, Yozgat State Hospital, Yozgat, Turkey \\ ${ }^{2}$ Department of Psychiatry, Kırklareli State Hospital, Kırklareli, Turkey
}

\begin{abstract}
Objective The purpose of this study was to examine personality traits of patients with major depressive disorder and explore the possible connections between personality and clinical and sociodemographic variables.

Methods The sociodemographic and clinical properties of 80 patients with major depression, who were euthymic according to Hamilton Depression Scale scores, were recorded. Their personality was evaluated by using Temperament and Character Inventory and results were compared with 80 age- and sex-matched healthy controls. We used general linear model analysis to evaluate the manner in which the variables contributed to TCI scores.

Results Remitted depressive patients scored significantly lower on on self-directedness and higher on harm avoidance than HC. Previous suicide attempts had a main effect only on harm avoidance while previous psychotic mood episodes were significantly associated with novelty seeking, self-directedness and cooperativeness. With respect to numeric clinical variables, only duration of illness was significantly and negatively correlated with NS and RD scores.

Conclusion Patients with euthymic major depressive disorder may have significantly different personality traits than the normal population, and patients with different clinical and sociodemographic characteristics may show different personality patterns. In addition, assessment of major depressed patients by means of the Temperament and Character Inventory may be helpful to get a deeper insight into those personality traits underlying suicidality and the emergence of psychotic mood episode. Psychiatry Investig 2012;9:119-126
\end{abstract}

Key Words Major depressive disorder, Personality, Suicide, Psychotic mood episode.

\section{INTRODUCTION}

Major depression is a chronic and disabling disorder with high rates of recurrence and depressive disorders are highly prevalent worldwide. ${ }^{1}$ Personality features may predispose an individual to depression; the personality can be modified after the onset of depressive episode; and the personality can modify the clinical presentation of a depressive episode, and also, depressive personality can be considered as a subtype of a depressive disorder. ${ }^{2-4}$ In Cloninger's psychobiologic model

Received: August 8, 2011 Revised: December 14, 2011

Accepted: December 16, 2011 Available online: April 30, 2012

$\bowtie$ Correspondence: Okan Ekinci, MD

Yozgat State Hospital, Psychiatry Department, Yozagt 66100, Turkey

Tel: +90-354-2121070, Fax: +90-354-2121071

E-mail: drokanekinci@yahoo.com

(a) This is an Open Access article distributed under the terms of the Creative Commons Attribution Non-Commercial License (http://creativecommons.org/licenses/bync/3.0) which permits unrestricted non-commercial use, distribution, and reproduction in any medium, provided the original work is properly cited. of temperament and character, relationships between the structure and development of personality and psychiatric disorders are described. This model postulates that personality is comprehensively developed with respect to genetic traits, learning, and insight into the self-concept. The model is based on 4 temperament and 3 character dimensions. The temperament factors of harm avoidance, novelty seeking, reward dependence, and persistence are considered to be biologically based and highly heritable individual differences in habits and skills. Character is a developmental construct consisting of self-concept about the values and goals that influence the significance of what is experienced. The character dimensions self-directedness, cooperativeness, and self transcendence mature in response to learning and life experiences and can influence the expression of temperament. ${ }^{5,6}$

Studies using the TCI to investigate personality factors in major depressive disorder (MDD) show consistent differences between MDD and healthy comparison subjects (HC). Sub- 
jects with MDD exhibit higher levels of harm avoidance and self-transcendence and lower levels of self-directedness and cooperativeness than HC, ${ }^{4,7}$ On the other hand, few studies have compared the TCI profiles of euthymic MDD patients and HC. These studies showed that remitted MDD patients continue to show higher harm avoidance scores and lower self-directedness scores compared to HC soon after the remission of their depressive episode..$^{7-9}$

However, to our knowledge, only one study has specifically assessed the relationship between clinical features and temperament and character traits in remitted MDD patients. ${ }^{9}$ The major limitation of that study on patients with MDD was that all patients were not euthymic and sample size of euthymic patients was too small, because mood states may affect the results. In addition, depressed MDD patients exhibit a characteristic cognitive bias as a result of their condition. This depressive cognitive dysfunction might influence either the selfreporting or the actual personality traits. ${ }^{5,10}$ Temperament and character traits have been researched and considered as important factors for suicidal behavior in recent years. ${ }^{11}$ On the other hand, previous research suggests that psychotic depressive patients have a more severe and chronic form of illness compared with those with non-psychotic major depression (NMD). However, there is little information about the relationship between personality and psychotic mood episodes although it is known that the personality can modify the clinical presentation of a depressive episode. ${ }^{9,12}$ Therefore, we also considered these clinical features as related factors when assessing personality.

In this study, we sought to clarify the relationship between personality, as measured by TCI, and MDD in euthymic phase. We hypothesized that eutymic MDD patients demonstrate a different personality profile compared to HC. Our another hypothesis was that some clinical appearances such as the history of suicide attempt and psychotic mood episode, would be differentially related to personality profile in subjects with remitted major depressive disorder.

\section{METHODS}

\section{Subjects}

This was a cross-sectional study. Four-hundred and fortysix consecutive patients with a diagnosis of major depressive disorder who were admitted in the period between April 2010 and January 2011 to our outpatient department, were preliminarily screened for the study. The diagnoses were made by a trained interviewer (AE) using the Structured Clinical Interview for DSM-IV (SCID-P) and were confirmed through a consensus meeting attended by two psychiatrists (including $\mathrm{OE}$ and YA). ${ }^{13-16}$ All evaluations were made by three research- ers. Clinical variables were collected by psychiatric interview and by review of the patient charts and inpatient files. The clinical state of patients was determined by the authors using SCID for DSM-IV and the Hamilton Depression Rating Scale (HDRS). All of the patients were in a state of remission at the time of testing. Remission was defined as a period of at least 2 months during which the subject had no significant signs or symptoms of the disorder (according to DSM-IV criteria) and during which the HDRS were below 6. Inclusion criteria consisted of being 18-55 years old and being in remission for 2 months (HDRS score $<6$ ). Subjects who had other disorders that could have influence on cognitive function (significant neurological and physical illness, substance abuse or dependence in the last year, electroconvulsive therapy in the preceding year, intoxication or cerebral trauma history), subjects who had comorbid axis II disorder were excluded. The study was reviewed and approved by our institutional review board. Before study-specific procedures were carried out, the study was thoroughly explained to subjects, and written informed consent was obtained.

From the initial sample of four-hundred and forty-six major depressive patients, one-hundred and seven patients were enrolled to the study according to our remission criteria. Among remitted depressive patients, 8 were excluded because they were diagnosed with comorbid substance use disorders, 6 were excluded because of comorbid medical or neurological illness, 13 were excluded because of comorbid axis II diagnosis. Thus, 80 consecutive remitted patients were included in the final sample. In addition, 80 control subjects matched for age, education and gender were tested. The control group comprised healthy volunteers with similar socio-cultural backgrounds to the patients. Controls were recruited from the general population through advertisements asking for the aid of unpaid volunteers. Controls were assessed by the HDRS. Turkish versions of the Structured Clinical Interview for DSM non-patients (SCID-NP) and SCID-II were also administered to the control group. ${ }^{16,17}$ They did not have any current or lifetime axis I or II disorder. Controls conformed to the same exclusion criteria as the participants with major depressive disorder. They also had no family history of major psychiatric illness (psychosis, affective disorder, suicide or alcohol and substance misuse) in a first-degree relative.

\section{Clinical assessment}

The 17-item version of the Hamilton Depression Rating Scale (HDRS) was used to assess severity of depression. ${ }^{18,19}$ Personality was assessed using the Temperament and Character Inventory (TCI) a 240-question self-report instrument. The TCI (version IX) was also reported to be a valid and reliable instrument for Turkish healthy and psychiatric popula- 
tions. ${ }^{20}$ According to Cloninger's psychobiological model, the temperament dimension Novelty Seeking (NS) is defined as a tendency to respond to novelty, impulsiveness and quick loss of temper and active avoidance to frustration. A second temperament dimension, Harm Avoidance (HA) is viewed as a bias in the inhibition of behaviors, such as pessimistic worry, passive dependent behaviors and rapid fatigability. The third temperament dimension, Reward Dependence (RD) is defined as a bias toward the maintenance of ongoing behaviors and is manifested in social attachment and dependence on approval of others. Persistence (PE) is defined as a tendency to perseverance despite frustration and fatigue. The character dimension, termed Selfdirectedness (SD), refers to self-determination, self-esteem and to the ability of an individual to control, regulate and adapt behavior to fit the situation in accord with personal goals and values. The second character dimension, Cooperativeness (CO), accounts for individual dif- ferences in identification with and acceptance of other people and measures aspects related to agreeability self-centered aggression and hostility. Self-transcendence (ST) refers to spiritual maturity, transpersonal identification and self-forgetfulness.

\section{Data analysis}

We used SPSS for Windows 16.0 version for all statistical analyses in this study. A confidence interval of $95 \%$ and a 2-tailed $\mathrm{p}$ value less than 0.05 was considered statistically significant for all analyses. Variables were tested for homogeneity of variance by using the Levene test and for normality of distribution using the Kolmogorov-Smirnov test. Data that departed significantly from normality of distribution or homogeneity of variance were analyzed nonparametrically. For a comparison of sociodemographic characteristics of patients and controls, $\chi^{2}$ test was used. Pearson's correlation was per-

Table 1. Demographic and clinical characteristics of subjects with major depressive disorder and healthy comparison subjects

\begin{tabular}{|c|c|c|c|c|}
\hline & & Major depressive disorder $(\mathrm{N}=80)$ & Healthy controls $(\mathrm{N}=80)$ & $\mathrm{p}$ \\
\hline Age & & $36.8 \pm 6.9$ & $31.6 \pm 4.4$ & 0.086 \\
\hline \multirow[t]{2}{*}{ Gender } & Female & $50(62.5 \%)$ & $40(50 \%)$ & 0.160 \\
\hline & Male & $30(37.5 \%)$ & $40(50 \%)$ & \\
\hline \multirow[t]{5}{*}{ Occupation } & Unemployed & $4(5.0 \%)$ & $9(1.9 \%)$ & $<0.001^{* *}$ \\
\hline & Worker & $12(15.0 \%)$ & $27(33.3 \%)$ & \\
\hline & Officer & $21(26.2 \%)$ & $44(64.8 \%)$ & \\
\hline & Retired & $11(13.8 \%)$ & $0(0.0 \%)$ & \\
\hline & Housewife & $27(33.8 \%)$ & $0(0.0 \%)$ & \\
\hline \multirow[t]{3}{*}{ Marital status } & Single & $12(15 \%)$ & $17(16.7 \%)$ & 0.120 \\
\hline & Married & $62(77.5 \%)$ & $63(83.3 \%)$ & \\
\hline & Widowed & $6(7.5 \%)$ & $0(0.0 \%)$ & \\
\hline \multirow[t]{2}{*}{ Smoking } & No & $50(62.5 \%)$ & $46(70.4 \%)$ & 0.362 \\
\hline & Yes & $30(37.5 \%)$ & $34(29.6 \%)$ & \\
\hline Length of education (years) & & $8.9 \pm 2.2$ & $9.2 \pm 2.9$ & 0.430 \\
\hline \multirow[t]{3}{*}{ Socioeconomic level } & Low & $13(16.2 \%)$ & $19(24.2 \%)$ & 0.112 \\
\hline & Medium & $28(35 \%)$ & $21(25.8 \%)$ & \\
\hline & High & $39(48.8 \%)$ & $40(50.0 \%)$ & \\
\hline \multirow[t]{2}{*}{ Family history of mental ilness } & No & $17(21.2 \%)$ & - & \\
\hline & Yes & $63(78.8 \%)$ & & \\
\hline \multirow[t]{2}{*}{ Previous suicide attempt } & No & $41(51.2 \%)$ & - & \\
\hline & Yes & $39(48.8 \%)$ & & \\
\hline \multirow[t]{2}{*}{ Previous psychotic mood episode } & No & $56(70 \%)$ & - & \\
\hline & Yes & $24(30 \%)$ & & \\
\hline Age at ilness onset & & $30.8 \pm 6.8$ & - & \\
\hline Duration of illness (years) & & $6.9 \pm 7.9$ & - & \\
\hline Number of hospitalisation & & $0.6 \pm 0.8$ & - & \\
\hline Number of depressive episodes & & $3.3 \pm 1.5$ & - & \\
\hline Number of psychotic mood episodes & & $0.4 \pm 0.7$ & - & \\
\hline
\end{tabular}

** $<<0.001$. NA: not applicable 
formed to analyze the correlation coefficients between mood state (scores of HAM-D), numeric clinical variables and TCI scores. To determine the factors that have association with TCI scores, first statistical analysis were performed by using 1-way analysis of variance with posthoc Tukey test and $t$ test for independent samples. A risk factor model was formed by using these results, and these variables were used for secondary analysis. Secondary analysis involved a multivariate linear regression analysis approach to analysis of covariance. Age and the years of education were continuous variables; gender, suicide history and previous psychotic mood episode were dichotomous categorical predictor variables; and TCI scores were dependent variables.

\section{RESULTS}

A total of 80 patients with MDD (50 women and 30 men) and 80 healthy controls ( 40 women and 40 men) completed the study. The mean age for patient groups was $36.8 \pm 6.9$ years and that for control group was $31.6 \pm 4.4$ years. Two groups were compared with regard to age, gender, education, occupation, socioeconomic class and status of smoking. As shown in Table 1, patients and controls did not differ significantly on any of these features, except of the occupation.

The duration of illness was $6.9 \pm 7.9$ years. The average age of the first depressive episode experienced by the subjects was $30.8 \pm 6.8$ years. The mean duration of remission was $5.07 \pm$ 2.34 months for patient sample. The mean number of depressive episodes, psychotic mood episodes and hospitalizations were $3.3 \pm 1.5 ; 0.4 \pm 0.7$ and $0.7 \pm 0.8$, respectively. Among the patients, $48.8 \%(\mathrm{n}=39)$ made at least 1 suicide attempt and $30 \%(\mathrm{n}=24)$ had at least 1 previous psychotic mood episode. Mean and SD for HAM-D scores were 1, 82 \pm 0.61 for patients sample and $0.25 \pm 0.44$ for control sample.

Regarding temperament traits, the scores of harm avoidance was substantially higher in subjects with depression than in healthy comparison subjects. No significant differences were found between the groups concerning novelty seeking, reward dependence and persistence scores, as shown in Table 2. Regarding character traits, patients with MDD scored significantly lower than healthy controls on the SD scores. No significant differences were found between the groups concerning self-transcendence and cooperativeness, as shown in Table 2. We next investigated the role of education, age and gender in these differences. We conducted GLM analyses with age and education as continuous predictors and gender as a categorical predictor, and TCI scores as dependent variables. Gender significantly contributed to scores on HA and P (F= 4.63, $\mathrm{df}=2, \mathrm{p}=0.03$ and $\mathrm{F}=4.48, \mathrm{df}=2, \mathrm{p}=0.03$, respectively). Male participants scored significantly higher on HA and $\mathrm{P}$ subscales of TCI (HA: $17.4 \pm 0.6$ versus $15.6 \pm 0.5 \mathrm{t}(132)=-2.7$ $\mathrm{p}=0.008 ; \mathrm{p}: 3.7 \pm 0.3$ versus $2.9 \pm 0.2 \mathrm{t}(132)=-2.17 \mathrm{p}=0.032)$. Age, education and the interaction of group and gender did not significantly contributed to any TCI score (Table 3). In addition, there was no effect of occupation on the differences of temperament and character between two groups in multivariate analysis $(\mathrm{F}=1.63, \mathrm{df}=14, \mathrm{p}=0.07)$.

NS and $\mathrm{RD}$ scores had negative correlations with duration of illness in subjects with MDD ( $\mathrm{n}=80)(\mathrm{r}=-0.247, \mathrm{p}<0.05$ and $\mathrm{r}=-0.241, \mathrm{p}<0.05$, respectively). We did not find any significant correlations between age, education, age at illness onset, HDRS scores, number of hospitalizations, number of depressive episodes, number of suicide attempts and psychotic mood episodes, and any TCI score. In addition, there was no significant correlation between duration of remission and any TCI subscale in depressive subjects.

In the patient sample, we investigated effects of age and years of education as continuous predictor variables, and gender, previous suicide attempt and previous psychotic mood episode as dichotomous categorical variables, on TCI scores. The results, summarized in Table 4, showed that education, age and gender did not significantly contribute to any TCI

Table 2. Temperament and Character Inventory $(\mathrm{TCl})$ scores in subjects with major depressive disorder and in healthy comparison subjects

\begin{tabular}{|c|c|c|c|c|}
\hline & Major depressive disorder $(\mathrm{N}=80)$ & Healthy controls $(\mathrm{N}=80)$ & $\mathrm{t}$ & $\mathrm{p}$ \\
\hline \multicolumn{5}{|l|}{ Temperament traits } \\
\hline Harm avoidance & $18.18 \pm 3.83$ & $11.45 \pm 5.04$ & $\mathrm{t}=-4.61, \mathrm{df}=132$ & $<0.001^{* *}$ \\
\hline Novelty seeking & $21.32 \pm 4.72$ & $21.66 \pm 3.29$ & $\mathrm{t}=-0.461, \mathrm{df}=132$ & 0.645 \\
\hline Reward dependence & $9.60 \pm 3.10$ & $10.28 \pm 2.44$ & $\mathrm{t}=-1.34, \mathrm{df}=132$ & 0.180 \\
\hline Persistence & $3.21 \pm 1.66$ & $3.44 \pm 2.44$ & $\mathrm{t}=-0.656, \mathrm{df}=132$ & 0.513 \\
\hline \multicolumn{5}{|l|}{ Character traits } \\
\hline Self-directedness & $24.69 \pm 7.12$ & $36.16 \pm 6.91$ & $\mathrm{t}=4.445, \mathrm{df}=132$ & $<0.001^{* *}$ \\
\hline Cooperativeness & $26.82 \pm 5.57$ & $24.11 \pm 4.58$ & $\mathrm{t}=1.87, \mathrm{df}=132$ & 0.063 \\
\hline Self-transcendence & $14.55 \pm 4.61$ & $16.0 \pm 4.84$ & $\mathrm{t}=-1.75, \mathrm{df}=132$ & 0.082 \\
\hline
\end{tabular}


Table 3. Temperament and Character Inventory $(\mathrm{TCl})$ scores in subjects with major depressive disorder versus comparison subjects: effect of age, gender, and education

\begin{tabular}{lccccrcc}
\hline & HA & NS & RD & p & SD & ST & CO \\
\hline Current age & $1.87(0.17)$ & $0.02(0.88)$ & $0.15(0.69)$ & $0.39(0.53)$ & $0.11(0.74)$ & $0.11(0.74)$ & $0.205(0.74)$ \\
Gender & $4.63(\mathbf{0 . 0 3})$ & $2.58(0.11)$ & $0.38(0.54)$ & $4.48(0.03)$ & $0.006(0.94)$ & $0.33(0.56)$ & $0.30(0.585)$ \\
Length of education & $0.58(0.45)$ & $0.03(0.86)$ & $0.15(0.70)$ & $3.19(0.08)$ & $1.78(0.18)$ & $0.01(0.93)$ & $0.45(0.501)$ \\
Group & $\mathbf{2 0 . 0 4 ( 0 . 0 0 )}$ & $0.71(0.402)$ & $0.81(0.37)$ & $0.001(0.98)$ & $\mathbf{1 8 . 5 7 ( 0 . 0 0 )}$ & $2.44(0.12)$ & $3.56(0.06)$ \\
Group X gender & $0.15(0.67)$ & $2.60(0.11)$ & $0.32(0.57)$ & $0.001(0.98)$ & $2.08(0.15)$ & $0.08(0.78)$ & $0.51(0.47)$ \\
\hline
\end{tabular}

Table shows F ratios from general linear model analysis; F df=1. Current age and years of education were continuous variables; group and gender were dichotomous categorical predictor variables; and TCI scores were dependent variables. $\mathrm{p}$ values of F ratios are in parentheses. Significant F ratios are shown in bold type. TCI: Temperament and Character Inventory, HA: harm avoidance, NS: novelty seeking, RD: reward dependence, P: persistence, SD: self-directedness, ST: self-transcendence, CO: cooperativeness

Table 4. Relationships between TCl scores and sociodemographic and clinical features in subjects with major depressive disorder

\begin{tabular}{lccccccc}
\hline & HA & NS & RD & p & SD & ST & CO \\
\hline Age & $2.87(0.09)$ & $0.62(0.43)$ & $0.09(0.76)$ & $1.21(0.276)$ & $1.22(0.27)$ & $0.12(0.73)$ & $0.76(0.38)$ \\
Gender & $0.88(0.35)$ & $3.63(0.06)$ & $0.87(0.35)$ & $1.64(0.204)$ & $2.13(0.15)$ & $0.51(0.48)$ & $0.13(0.71)$ \\
Length of education & $0.03(0.85)$ & $1.44(0.23)$ & $0.02(0.89)$ & $0.72(0.401)$ & $2.09(0.15)$ & $0.15(0.69)$ & $0.47(0.49)$ \\
Previous suicide attempt & $\mathbf{4 2 . 3 6 ( 0 . 0 0 )}$ & $3.59(0.06)$ & $0.01(0.94)$ & $0.06(0.81)$ & $1.65(0.20)$ & $1.36(0.25)$ & $1.52(0.22)$ \\
Previous psychotic mood episode & $2.95(0.09)$ & $\mathbf{8 . 9 8 ( 0 . 0 0 4 )}$ & $0.84(0.36)$ & $7.41(0.008)$ & $\mathbf{3 7 . 4 ( 0 . 0 0 )}$ & $1.98(0.16)$ & $\mathbf{8 . 6 2 ( 0 . 0 0 4 )}$ \\
Previous suicide attempt X previous & $1.88(0.17)$ & $0.12(0.72)$ & $3.52(0.07)$ & $0.01(0.757)$ & $0.03(0.87)$ & $0.02(0.89)$ & $0.21(0.65)$ \\
psychotic mood episode & & & & & & & \\
\hline
\end{tabular}

Table shows $\mathrm{F}$ ratios from general linear model analysis; $\mathrm{F} \mathrm{df}=1$. Current age and years of education were continuous variables; suicide history, previous psychotic mood episode and gender were dichotomous categorical predictor variables; and TCI scores were dependent variables. $\mathrm{p}$ values of $\mathrm{F}$ ratios are in parentheses. Significant $\mathrm{F}$ ratios are shown in bold type. TCI: Temperament and Character Inventory, HA: harm avoidance, NS: novelty seeking, RD: reward dependence, P: persistence, SD: self-directedness, ST: self-transcendence, CO: cooperativeness

score. Previous suicidal attempt significantly contributed to HA scores while previous psychotic mood episode significantly related to NS, SD and CO scores. HA was significantly higher in subjects with depression who had made suicide attempts than in those who had not $(22.2 \pm 2.01$ versus $14.9 \pm 4.5$; $\mathrm{t}(78)=9.29, \mathrm{p}<0.001)$. The subjects with depression who had experienced psychotic mood episode scored significantly higher on NS and significantly lower on $\mathrm{CO}$ and SD subscales of TCI than those who had not $(\mathrm{t}=-3.241, \mathrm{df}=78, \mathrm{p}=0.002$; $\mathrm{t}=4.414, \mathrm{df}=78, \mathrm{p}<0.001$ and $\mathrm{t}=8.436, \mathrm{df}=78 \mathrm{p}<0.001$, respectively). In addition, there was no effect of the interaction between suicidal attempt and psychotic mood episode on TCI scores.

\section{DISCUSSION}

Present study mainly demonstrated that euthymic MDD patients present a different personality profile than $\mathrm{HC}$, with higher scores on harm avoidance and lower scores on self-directedness. In addition, MDD patients with suicide attempts exhibited higher HA scores while those experienced at least one psychotic mood episode significantly scored higher on NS and lower on CO and SD than those without these features. With respect to numeric clinical variables, duration of illness was significantly and negatively correlated with NS and $\mathrm{RD}$ scores. In the present study, we used clear and rigorous remission criteria when assessing our subjects and the study sample comprised of only remitted depressive patients. Our sample size was relatively larger than remitted patient group in the study of Nery et al..$^{9}$ In addition, another limitation of their study is that the authors did not consider important clinical features such as suicidality and presence of psychotic mood episode when assessing personality.

Our findings confirm prior reports of higher HA scores among MDD subjects compared with healthy controls. Previous studies found results similar to ours, i.e., higher harm avoidance and lower self-directedness in MDD patients compared to HC. ${ }^{4,7,8,21}$ Harm avoidance, defined as a tendency to respond intensely to signals of aversive stimuli, thereby learning to avoid punishment and novelty appears to be a measure that is elevated during depressive states. ${ }^{22,23}$ There is evidence for a state dependency of personality traits as measured by the TCI, in particular a decrease in harm avoidance as depression improves. Moreover, Mulder and Joyce ${ }^{23}$ have reported a significant difference between HA scores assessed initially and after 6 weeks of antidepressant treatment.

In the present study, HA scores were measured in only remitted MDD patients and HC. Also, it is possible that higher 
HA is still associated with residual mood symptoms. However, we consider this unlikely because we have used strict remission criteria and there was no significant correlation between patient scores on scale of mood states, duration of remission and HA. Therefore, the relatively high level of HA found in the patients is not completely state dependent and may be a stable component that is not merely a manifestation of mood state. This association could have different origins: it could be a consequence of repeated mood episodes, a risk factor for the disorder, or a manifestation of an independent factor linked with the biological causes of the disorder. In a meta-analysis study, Kampman and Poutanen ${ }^{24}$ postulated a definite and undisputable association between HA temperament dimension and occurrence or severity of current depressive symptoms and a similar, but more diffuse association between HA and depressive trait and they suggested that high HA may indicate susceptibility to depression.

In the present study, we did not find any differences in RD, NS and $\mathrm{P}$ scores between patients and control groups. Kampman et al. ${ }^{25}$ found a slightly higher RD score for the total patient sample at baseline and for men at endpoint. The authors indicated that this result is contradictory to some earlier findings within general population and they suggested that the variation in these findings may indicate that the meaning of $\mathrm{RD}$ as a vulnerability factor is limited and RD might be statedependent in depression. The studies regarding other temperament dimensions (NS and P) have heterogeneous findings. It has been suggested that it is likely related to different study methodology, including patient selection, sample size, type of treatment and follow-up time. Kampman et al. ${ }^{25}$ proposed that the differences in NS and P scores in their study in the opposite direction than with HA can be regarded as clinically significant findings associated with depression.

Another consistent finding from previous studies of personality dimensions in depressive disorders is that low SD (defined as the ability of an individual to adapt, regulate, and control behavior to fit situations in accord with his chosen goals and values) is associated with depression. This finding, also supported in our study, supports the idea that immaturity of self-concept is a vulnerability factor for negative affectivity in general. ${ }^{26}$ As with HA, SD scores are also influenced by depressed mood at the time of assessment. ${ }^{4,21,27}$ Experiencing a depressive episode may have adverse consequences for the progressive maturation of a character trait such as self-directedness, as by definition character is influenced by the multiple socio-cultural experiences a person has in his/her life. ${ }^{5}$ Alternatively, self-directedness may be a vulnerability factor for the development of depression, with people who are less resourceful, purposeful and self-accepting being more at risk to develop depression.
We did not find any significant correlations between age, age at onset, number of hospitalizations, number of depressive episodes and any personality score. Conrad et al. ${ }^{11}$ found a positive correlation between harm avoidance and the number of depressive episodes a patient has experienced. Another study also found that single episode MDD patients show lower harm avoidance than recurrent MDD patients. Repeated depressive episodes may cause prolonged or permanent increases in harm avoidance. ${ }^{7}$ However, our findings suggest that some personality traits contribute to onset of depressive disorder rather than a consequence of repeated episodes of illness or the sequel of disease process and may be more related to a characteristic personality profile of MDD patients than to a depressive state. This hypothesis is supported by other findings that never-depressed siblings of MDD patients are intermediate in personality traits between cases and controls, suggesting that personality traits might be vulnerability markers for major depression. ${ }^{21}$

Our study shows that one dimension of temperament may discriminate previous suicide attempters and nonsuicide attempters, harm avoidance. HA scores are higher in suicide attempters than in nonsuicide attempters. Our study confirms several previous studies observing higher harm avoidance in suicide attempters. ${ }^{11,28,29}$ There is a lot of evidence confirming Cloninger's hypothesis that serotonin constitutes neurotransmission within the behavioural inhibition subsystem underlying the temperament dimension harm avoidance. Dysfunction of the serotonergic system also has an important role in the neurochemistry and genetics of suicidal behaviour. ${ }^{30-32} \mathrm{~A}$ recent study investigated a large number of mood disorder patients and did not find relevant differences between patients with or without suicide attempt. ${ }^{28}$ The authors conclude that this result could be due to the effect of mood on personality as measured by the TCI and emphasize the difficulty of disentangling the personality profile of suicide attempters from their psychopathology as their methodological approach did not control for depression. Conrad et al. ${ }^{11}$ have been made a methodological approach took the state dependency of personality dimensions into account by entering Hamilton depression scores as a covariate into their statistical analysis. However, only remitted patients were enrolled to the present study and therefore our findings differ from other studies focusing on interepisodic HA scores. So that, this finding indicates that the interventions which decreases HA in euthymic phase may decrease suicidality in major depression and should be confirmed by longitudinal and intervention studies.

Another important result of this study was that depressive subjects with previous psychotic mood episode had higher NS scores and lower CO and SD than those without. Psychot- 
ic major depression can be differentiated from NMD based on a number of neurobiological abnormalities in areas such as brain structure, hypothalamic-pituitaryadrenocortical axis activity, dopaminergic and serotonergic neurotransmission, and neuropsychological functioning (eg, motor skills, attention, concentration). ${ }^{33,34}$ Higher NS in patients with psychotic mood episode might be explained by dopaminergic and serotonergic abnormalities because NS has been suggested to be linked to the dopamine and serotonin system. ${ }^{35,36}$ It is well known that psychotic features can be an indicator of bipolarity in depressive disorders. The combination of higher NS and lower $\mathrm{CO}$ and SD observed in our psychotic MDD were similar to the findings reported in bipolar patients. Although our patients were carefully screened for the presence of previous manic/hypomanic symptoms, we cannot completely rule out the possibility that some of our patients are closely related to this "soft" BD spectrum. ${ }^{37}$ Otherwise, this personality combination could made depressive patients more vulnerable to experience psychotic mood episode or multiple episodes of psychotic depression cause permanent damage to the part of the brain related to personality that this may somehow contribute to kindling. ${ }^{38,39}$ It seems difficult to differentiate between the "cause" and the "consequence." Distinguishing between these 2 possible explanations is only possible in longitudinal studies of patients before and after the onset of recurrent depression.

As with many studies in the field, sample size was relatively small. As with most studies on patients recovered from depression, all patients were on antidepressant medication, which may affect personality measures. None of our patient group had any other psychiatric comorbidity and the sample may not be representative of the clinical population. Having such a sample however, suggests that these deficits are specific to depression and are not because of other comorbidities. An obvious drawback of the TCI data is that they are based on self-report. This is a cross-sectional study of baseline parameters; hence the longer term associations between personality and clinical properties were not addressed. There is a need to examine the longitudinal course of illness in these subjects and evaluate the complex inter-relationships among personality, sociodemographic and clinical properties as well as the impact of psychopharmacological and psychosocial interventions.

In conclusion, based on our results, patients with euthymic major depressive disorder may have significantly different personality traits than the normal population, and patients with different clinical and sociodemographic characteristics may show different personality patterns. The combination of high HA with low SD may be specific to major depression. In addition, assessment of major depressed patients by means of the Temperament and Character Inventory may be helpful to get a deeper insight into those personality traits underlying suicidality and the emergence of psychotic mood episode.

\section{REFERENCES}

1. Ayuso-Mateos JL, Vázquez-Barquero JL, Dowrick C, Lehtinen V, Dalgard OS, Casey P, et al. Depressive disorders in Europe: prevalence figures from the ODIN study. Br J Psychiatry 2001;179:308-316.

2. Akiskal HS, Hirschfield RM, Yerevanian BI. The relationship of personality to affective disorders. Arch Gen Psychiatry 1983;40:801-810.

3. Hirschfeld RMA, Shea MT, Holzer CE. Personality Dysfunction and Depression. In: Honing A, van Praag HM, Editors. Depression: Neurobiological, Psychopathological and Therapeutic Advances. New York: John Wiley, 1997, p.327-341.

4. Hansenne M, Reggers J, Pinto E, Kjiri K, Ajamier A, Ansseau M. Temperament and character inventory (TCI) and depression. J Psychiatr Res 1999;33:31-36.

5. Cloninger CR, Svrakic DM, Przybeck TR. A psychobiological model of temperament and character. Arch Gen Psychiatry 1993;50:975-990.

6. Cloninger CR, Przybeck TR, Svrakic DM, Wetzel RD. The Temperament and Character Inventory (TCI): A Guide to Its Development and Use. Washington University, St Louis (Mo): Center for Psychobiology of Personality; 1994

7. Richter J, Eisemann M, Richter G. Temperament and character during the course of unipolar depression among inpatients. Eur Arch Psychiatry Clin Neurosci 2000;250:40-47.

8. Smith DJ, Duffy L, Stewart ME, Muir WJ, Blackwood DH. High harm avoidance and low self-directedness in euthymic young adults with recurrent, early-onset depression. J Affect Disord 2005;87:83-89.

9. Nery FG, Hatch JP, Nicoletti MA, Monkul ES, Najt P, Matsuo K, et al. Temperament and character traits in major depressive disorder: influence of mood state and recurrence of episodes. Depress Anxiety 2009; 26:382-388.

10. Beck AT. The current state of cognitive therapy: a 40-year retrospective. Arch Gen Psychiatry 2005;62:953-959.

11. Conrad R, Walz F, Geiser F, Imbierowicz K, Liedtke R, Wegener I. Temperament and character personality profile in relation to suicidal ideation and suicide attempts in major depressed patients. Psychiatry Res 2009;170:212-217.

12. Gaudiano BA, Miller IW. Dysfunctional cognitions in hospitalized patients with psychotic versus nonpsychotic major depression. Compr Psychiatry 2007;48:357-365.

13. First MB, Spitzer RL, Gibbon M. Structured Clinical Interview for DSM-IV Axis I Disorders (SCID), Clinician Version. Washington, DC: American Psychiatric Press; 1996.

14. First MB, Spitzer RL, Benjamin LS, Gibbon M, Williams JBW. Structured Clinical Interview for DSM-IV AXIS II Personality Disorders (SCID-II). Washington, DC: American Psychiatric Press; 1997.

15. Corapcioglu A, Aydemir O, Yildiz M. Structured Clinical Interview for DSM-IV (SCID-IV), Turkish Version (Turkish). Ankara: Hekimler Yayin Birligi; 1999.

16. Coşkunol H, Bagdiken, Sorias S. SCID-II (Turkce versiyonu) goruşmesinin kişilik bozukluklarındaki guvenilirliği. Turk Psikoloji Dergisi 1994;9:26-29.

17. Sorias S. DSM-III-R Yapılandırılmış Klinik Görüşmesi Türkçe versiyonu (SCID). Bornova: Ege Üniversitesi; 1990.

18. Hamilton M. A rating scale for depression. J Neurol Neurosurg Psychiatry 1960;23:56-62.

19. Akdemir A, Orsel SD, Dag I, Turkcapar MH, Iscan N, Ozbay H. The validity and reliability of the Hamilton Depression Rating Scale and its clinical use. Psikiyatri Psikol Psikofarmakol Derg 1996;4:251-259.

20. Kose S, Sayar K, Kalelioglu U, Aydin N, Celikel FC, Gulec H, et al. Normative data and factorial structure of the Turkish version of the Temperament and Character Inventory. Compr Psychiatry 2009;50:361- 
368.

21. Farmer A, Mahmood A, Redman K, Harris T, Sadler S, McGuffin P. A sib-pair study of the Temperament and Character Inventory scales in major depression. Arch Gen Psychiatry 2003;60:490-496.

22. Chien AJ, Dunner DL. The Tridimensional Personality Questionnaire in depression: state versus trait issues. J Psychiatr Res 1996;30:21-27.

23. Mulder RT, Joyce PR. Relationships of the Tridimensional Personality Questionnaire to mood and personality measures for depressed patients. Psychol Rep 1994;75:1315-1325.

24. Kampman O, Poutanen O. Can onset and recovery in depression be predicted by temperament? A systematic review and meta-analysis. J Affect Disord 2011;135:20-27.

25. Kampman O, Poutanen O, Illi A, Setälä-Soikkeli E, Viikki M, Nuolivirta $\mathrm{T}$, et al. Temperament profiles, major depression, and response to treatment with SSRIs in psychiatric outpatients. Eur Psychiatry 2012;27: 245-249.

26. Matsudaira T, Kitamura T. Personality traits as risk factors of depression and anxiety among Japanese students. J Clin Psychol 2006;62:97109.

27. Hirano S, Sato T, Narita T, Kusunoki K, Ozaki N, Kimura S, et al. Evaluating the state dependency of the Temperament and Character Inventory dimensions in patients with major depression: a methodological contribution. J Affect Disord 2002;69:31-38.

28. Calati R, Giegling I, Rujescu D, Hartmann AM, Möller HJ, De Ronchi $\mathrm{D}$, et al. Temperament and character of suicide attempters. J Psychiatr Res 2008;42:938-945.

29. Rothenhäusler HB, Stepan A, Kapfhammer HP. Soluble interleukin 2 receptor levels, temperament and character in formerly depressed suicide attempters compared with normal controls. Suicide Life Threat Behav 2006;36:455-466.

30. van Heeringen K, Audenaert K, Van Laere K, Dumont F, Slegers G, Mertens J, et al. Prefrontal 5-HT2a receptor binding index, hopeless- ness and personality characteristics in attempted suicide. J Affect Disord 2003;74:149-158.

31. Peirson AR, Heuchert JW, Thomala L, Berk M, Plein H, Cloninger CR. Relationship between serotonin and the temperament and character inventory. Psychiatry Res 1999;89:29-37.

32. Ebstein RP. The molecular genetic architecture of human personality: beyond self-report questionnaires. Mol Psychiatry 2006;11:427-445.

33. Wheeler Vega JA, Mortimer AM, Tyson PJ. Somatic treatment of psychotic depression: review and recommendations for practice. J Clin Psychopharmacol 2000;20:504-519.

34. Tyrka AR, Price LH, Mello MF, Mello AF, Carpenter LL. Psychotic major depression: a benefit-risk assessment of treatment options. Drug Saf 2006;29:491-508.

35. Huang HY, Lee IH, Chen KC, Yeh TL, Chen PS, Yang YK, et al. Association of novelty seeking scores and striatal dopamine $\mathrm{D}_{2} / \mathrm{D}_{3}$ receptor availability of healthy volunteers: single photon emission computed tomography with ${ }^{123}$ i-iodobenzamide. J Formos Med Assoc 2010;109: 736-739.

36. Nakamura Y, Ito Y, Aleksic B, Kushima I, Yasui-Furukori N, Inada T, et al. Influence of HTR2A polymorphisms and parental rearing on personality traits in healthy Japanese subjects. J Hum Genet 2010;55:838841.

37. Jylhä P, Mantere O, Melartin T, Suominen K, Vuorilehto M, Arvilommi $\mathrm{P}$, et al. Differences in temperament and character dimensions in patients with bipolar I or II or major depressive disorder and general population subjects. Psychol Med 2011;41:1579-1591.

38. Post RM, Leverich GS, Kupka RW, Keck PE Jr, McElroy SL, Altshuler $\mathrm{LL}$, et al. Early-onset bipolar disorder and treatment delay are risk factors for poor outcome in adulthood. J Clin Psychiatry 2010;71:864-872.

39. Post RM, Rubinow DR, Ballenger JC. Conditioning and sensitization in the longitudinal course of affective illness. Br J Psychiatry 1986;149: 191-201. 